\title{
FLEXIBILIZAÇÃO DA LEGISLAÇÃO TRABALHISTA
}

Renata Cristina de Oliveira Alencar Silva

Osvaldo Alencar Silva"

SUMÁRIO: 1. Introdução. 2. Flexibilização e desregulamentação. 2.1. Análise conceitual. 2.2. posições da doutrina. 3. A Flexibilização no Direito Brasileiro. 3.1. Análise do Texto do Projeto. 3.1.1. Discussôes acerca do Artigo $1^{a}$ e parágrafos. 3.1.2. Análise do artigo 2. 4. Conclusão. 5 Bibliografia.

SUMARY: 1. Introduction. 2. Flexibilization and desregulamentation. 1.2. Conceitual Analysis 1.2. Doctrine Positions. 3. The Flexibilização in the Brazilian Law. 3.1. Analysis of the Text of the Project. 3.1.1. Analysis of the article $1^{a}$ and its paragrafs. 3.1.2. Analysis of the article $2^{a} .4$. Conclusion. 5 Bibliography.

SUMARIO: 1. Introducción. 2. Flexibilización y desregulamentación. 1.2. Análisis del concepto. 1.2. Las posiciones de la doctrina. 3. El Flexibilización en la Ley brasileña. 3.1. Análisis del Texto del Proyecto. 3.1.1. Análisis del artículo $1^{a}$ y sus párrafos. 3.1.2. Análisis del artículo $2^{a}$. 4. conclusión. 5 Bibliografía.

RESUMO: O artigo analisa a proposta do Governo tendente a flexibilizar as normas reguladoras das relações trabalhistas. Para tanto, estuda as normas que regulam os direitos trabalhistas no ordenamento jurídico Brasileiro, investigando os fatores sociais, econômicos e históricos que influenciaram na criação do instituto da flexibilização. Avalia as posições doutrinárias favoráveis e contrárias à sua adoção, bem como sua compatibi-

Mestranda em Direito Negocial pela Universidade Estadual de Londrina. Especialista em Direito Empresarial pela Universidade Estadual de Londrina. Advogada em Londrina, Paraná. E-mail: renataadv@bol.com.br

Pós graduando en Direito Enapresarial pela Universidade Estadual de Londrina. Advogado em Londrina, Paraná. E-mail: osvaldo@depaulamachadoadvogadosadv.br 
lidade com a norma constitucional brasileira. Discorre acerca da posição das entidades sindicas, a quem, pela proposta governamental, incumbe a tarefa de negociar os direitos trabalhistas como forma de sobrepó-los aos direitos legislados. Avalia os termos do Proje-

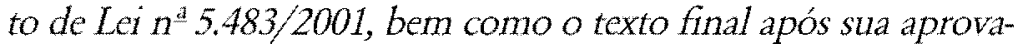
ção.

ABSTRACT: The article analyzes the Brazilian Government proposal to become flexible the labor relations norms. Studies the Brazilian Norms about labor relations, investigating the historical, economic, and social factors that influenced in the creation of the institute from the flexibilization. It evaluates the favorable and contrary doctrinary positions to its adoption, as well as its compatibilization with Brazilian Constitutional Norm. Studies about the union entities position, who, by the governmental proposal, have the responsibility of negotiate the labor norms. It evaluates the Law Project $n^{-3} 5.483 / 2001$, as well as the final text after his approval.

RESUMEN: El artículo analiza la propuesta del Gobierno de Brasil de tornar flexible las normas de las relaciones del trabajo. Estudia las Normas de Brasil acerca de relaciones de trabajo, investigando los factores históricos, económicos y sociales que influyeron en la creación del instituto del flexibilización. Avalia las posiciones favorables y contrarias de la doutrina de su adopción, así como su compatibilidad con la Constituición Brasileña. Estudia acerca de la posición de las entidades sindicales, a que, por la propuesta gubernamental, tienen la responsabilidad de negociar las normas del trabajo. Evalúa el Proyecto de la Ley n. ${ }^{-} 5483 / 2001$, así como el texto final después de su aprobación.

PALAVRAS-CHAVE: Flexibilização. Desregulamentação. Trabalho. Sindicato. Normas Trabalhistas.

KEY-WORDS: Flexibilization. Desregulamentation. Work. Union. Labor Norms.

PALABRAS-LLAVES: Flexibilización. Desregulamentación. Trabajo. Sindicato. Normas del Trabajo. 


\section{Introdução}

A aprovação pela Câmara dos Deputados do Projeto de Lei 5.483/ $2001^{1}$ acirrou as discussões acerca da adoção do instituto da flexibilização pelo ordenamento jurídico brasileiro.

Organizações de trabalhadores uniram suas vozes a fim de questionar a necessidade de se flexibilizar o modelo de normatização dos direitos trabalhistas adotados pelo Estado Brasileiro.

O fim do século XX e início do século XXI é marcado por crise bastante complexa, na medida em que as promessas de liberdade, igualdade e fraternidade não foram cumpridas. E tudo indica que não o serão.

A globalização da economia constitui-se na afirmação da hegemonia mundial alcançada pelo capital na segunda metade do século XX. Os conceitos de Estado e Soberania foram obrigatoriamente repensados.

O capital não tem mais nacionalidade, foi mundializado. Fala-se em aldeia global, preconizando-se a idéia (ainda que vaga e futura) de Estado único, conforme anotado por Kelsen². O comércio entre Estados derruba barreiras. Formam-se blocos econômicos entre Estados soberanos circunvizinhos. O capital exige que estes mesmos blocos se expandam, tornando-se megablocos econômicos. Por esse motivo, a globalização é chamada de a era das relações externas.

O Estado não é o único a moldar-se aos interesses do capital mundializado. O trabalho também se encontra pressionado a ceder aos seus interesses.

A flexibilização das normas reguladoras do Direito do Trabalho origina-se na Europa. De acordo com a concepção econômica, o desenvolvimento do capital determina que os direitos trabalhistas sejam revistos e repensados, na medida em que se colocam como óbice ao desenvolvimento pleno e ao acúmulo do capital.

Portanto, embora o presente trabalho analise os aspectos jurídicos do instituto da flexibilização, é importante salientar que sua origem está ligada à economia, nascida no momento em que esta ciência busca formas de compatibilizar as duas forças antagônicas, porém complementares que são o capital e o trabalho.

A flexibilização se mostra como sendo o instituto através do qual os direitos trabalhistas são revistos e repensados no ordenamento jurídico e, em algumas hipóteses, extintos.

\footnotetext{
A proposta recebeu 264 votos favoráveis e 213 votos contrários, contando anda com 2 abstençöes. KELSEN, H. Teoria Pura do Direito. Tradução: Joäo Baptista Machado. 5 ed., São Paulo: Martins Fontes, 1996 , p. 364.
} 
Pretende o presente estudo analisar o texto do Projeto de Lei 5.483/ 2001, aprovado pela Câmara dos Deputados em dezembro de 2001, sob a roupagem que lhe conferiu a emenda substitutiva ${ }^{3}$, antes da votação pelo Senado Federal.

\section{Flexibilização e destegulamentação}

Flexibilização e desregulamentação não se constituem em expressões sinonimas que designariam o mesmo instituto, muito embora, a despeito da cizânia conceitual em relação a ambos os vocábulos, não seja raro se constatar a utilização de um ou outro para designarem o mesmo conjunto de situações.

Como bem salienta Arnaldo Süssekind ${ }^{4}$, com a flexibilização, os sistemas legais prevêem fórmulas opcionais ou flexíveis de estipulação de condições de trabalho, seja pelos instrumentos da negociação coletiva, ou pelos contratos individuais de trabalho, seja pelos próprios empresários.

Para ele, a flexibilização amplia o espaço para a complementação ou suplementação do ordenamento legal, permitindo ainda a adaptação de normas cogentes a peculiaridades regionais, empresariais ou profissionais. Além disso, admite derrogações de condições anteriormente ajustadas, para adapta-las a situações particulares.

Contudo, Sussekind entende que a desregulamentação do Direito do Trabalho não se confunde com flexibilização. A primeira retira a proteção do Estado ao trabalhador, permitindo que a autonomia privada, individual ou coletiva regule as condiçōes de trabalho e os direitos e obrigações advindos da relação de emprego. A segunda pressupõe a intervenção estatal, ainda que básica, com normas gerais que garantem a vida do trabalhador com dignidade.

Assim, a desregulamentação do Direito do Trabalho se constitui em uma forma mais radical de flexibilização, na medida em que o Estado retiraria toda a proteção normativa até então conferida aos trabalhadores, incluindo-se as garantias mínimas. Nesta hipótese, prevaleceria de forma integral a autonomia da vontade das partes contratantes (privada ou coletiva), sendo que esta contratação não encontraria um patamar limítrofe mínimo ou máximo definido pelo Estado.

\footnotetext{
3 Emenda substitutiva é a apresentada como sucedânea à parte de outra proposição, denominandose substitutivo quando a alterar, substancial ou formalmente, em seu conjunto. In: Manua! Virtual de Processo Legislativo. Disponivel em: camaragov.br/internet/Processo/Processolegislativo.pdf. Acesso em: 01/072001.

+ SUSSEKIND, A. Instituiçoes de Direito do Trabalho. São Paulo: LTr, 1999, p. 213-4.
} 
A contrário senso, a flexibilização pressupõe a intervenção Estatal assegurando garantias mínimas aos trabalhadores.

Por tal razão, desregulamentação é vocábulo que deve ser restrito ao direito coletivo do trabalho, não se aplicando ao direito individual do trabalho para o qual existe a palavra flexibilização. Assim, desregulamentase o coletivo e flexibiliza-se o individual. Desregulamentação seria a política legislativa de redução da interferência da lei nas relaçóes coletivas de trabalho, para que se desenvolvam segundo o principio da liberdade sindical e das representações de trabalhadores. ${ }^{5} \mathrm{O}$ Estado deixa de interferir nas relações de trabalho, deixando para o sindicato das categorias esse papel.

Por constituir-se a desregulamentação na ausência de garantias mínimas fixadas pelo Estado, a viabilidade de sua adoção somente se verificaria em sociedades cujos trabalhadores fossem detentores de um bom nível de escolaridade e cujas entidades sindicais representativas já se encontrassem fortalecidas e amadurecidas suficientemente a fim de tornar possível uma negociação coletiva que redundasse na garantia de alguns direitos mínimos aos trabalhadores.

A realidade brasileira demonstra que nem os trabalhadores e nem as entidades sindicais nacionais se encontram dotados de tais características, razão pela qual não há como se vislumbrar a possibilidade de adoção deste instituto em nosso ordenamento jurídico.

Do ponto de vista dos trabalhadores e das entidades sindicais, não há interesse na flexibilização, pois esse instituto traz consigo a idéia de revogar direitos há muito conquistados pelos trabalhadores. Em sentido pior entende-se a desregulamentação.

Segundo Jasna Petrovich':

uma campanha real do Banco Mundial e do Fundo Monetário Internacional está atualmente em curso em quase todos os países da região, visando revisões urgentes em relação às legislações trabalhistas $\mathrm{em}$ todos os países a fim de assegurar a liberalização do mercado de trabalho, a flexibilização das relações de trabalho e a redução de direitos dos trabalhadores. Esta é uma tentativa de atacar as uniões de comércio, motivada por um desejo de reduzir sua influência.

Acima de tudo, os direitos dos trabalhadores são menos observados em páses com uma entrada intensa de capital externo, isto é, em países europeus Bálticos e centrais?.

\footnotetext{
"NASCIMENTO, A. M. Direito do Trabalho na Constituição de 1988. São Paulo: Saraiva, 1989 , p. 174. "Editora chefe da Conferencia Internacional da União Européia Central e Oriental e coordenadora do denominado orgão ICFTU CEE, em Maio de 2002.

"Howeyer, a real campaign of the Worid Bank and the International Monetary Fund is currently under way in almost all countries of the region, aiming at urgent new revisions in labor laws in all of the countries in order to ensure the liberalization of the labor market, flexiblization of labor relations and reduction of workers rights. This is an attempt to attack trade unions, and motivated by a desire to reduce their influence. Overall, workers rights are least observed in countries with a more intenswe entry of international and foreign capital, that is, in Baltic and Contral European countries. In: Revista Económica Europèa Multinational Monitor. Maio, 2002. Disponivel em: htip//multinationalmonitororg/mm2002/02mav/mavo2interviewpetrovic.html. Acesso 02/07/2002.
} 
Portanto, vislumbra-se claramente que o interesse capitalista se encontra por trás da implementação de tais institutos, razão pela qual é imprescindivel que a classe trabalhadora nacional se conscientize a este respeito a fim de que possa se posicionar com segurança acerca do que se pretende implementar no ordenamento juridico nacional.

\subsection{Análise Conceitual}

O conceito de flexibilização é bastante questionado. Para Amauri Mascaro Nascimento ${ }^{8}$ a flexibilização do direito do trabalho é uma corrente de pensamento, por meio da qual necessidades de natureza econômica justificam a violação de direitos dos trabalhadores.

Dentre os direitos violados estaria a estabilidade no emprego, as limitaçōes à jornada diária de trabalho, substituídas por um banco de horas anual, o afastamento sistemático do direito adquirido pelo trabalhador e que ficaria ineficaz sempre que a produção econômica o exigisse. Ou seja, flexibilização é o crescimento do direito potestativo do empregador.

Portanto, fica demonstrado que o real objetivo do instituto, que é o de privilegiar o capital em detrimento do trabalho.

Sérgio Pinto Martins define flexibilização do Direito do Trabalho como sendo o conjunto de regras que tem por objetivo instituir mecanismos tendentes a compatibilizar as mudanças de ordem econômica, tecnológica, política ou social existentes na relação entre o capital e o trabalho'.

No entanto, tal compatibilização visa, em última instância, encontrar fórmulas para aumentar o capital ou tornar o processo produtivo menos oneroso, em detrimento dos direitos conferidos aos trabalhadores.

Arnaldo Süssekind ${ }^{10}$ cita Orlando Teixeira Filho da Costa quando este conceitua flexibilização como sendo:

o instrumento ideológico neoliberal e pragmático de que vêm se servindo os países de economia de mercado, para que as empresas possam contar com mecanismos capazes de compatibilizar seus interesses e os dos seus trabalhadores, tendo em vista a conjuntura mundial, caracterizada pelas rápidas flutuações do sistema econômico, pelo aparecimento de novas tecnologias e outros fatores que exigem ajustes inadiáveis.

\footnotetext{
NASCIMENTO, A. M. Curso de Direito do Trabalho. $17^{\circ}$ ed., São Paulo: Saraiva, 2001, p. 120.

"MARTINS, S. P. Flexibilização das Condições de Trabalho, São Paulo: Atlas, 2000, p.25.

" FILHO DA COSTA, O. T. apud SÜSSEKIND, A.; MARANHÄO, D; VIANNA, S.; TEIXEIRA, L. Instituições de Direito do Trabalho. $18^{2}$ ed., Vol I , São Paulo: LTr, 1999, p, $215-216$.
} 
No entanto, os ajustes inadiáveis a que se refere não podem redundar em prejuízo aos direitos trabalhistas conquistados ao longo dos séculos. Se flexibilizar é compatibilizar direito e economia, devem as respectivas entidades sindicais representativas dos trabalhadores e, independentemente de tal representação, os próprios trabalhadores, estarem atentos a todas as propostas neste sentido, posto que, uma vez derrogado ou flexibilizado eventual direito, dificilmente o capital se curvará à possibilidade de se o adotar novamente.

Já Lourival José de Oliveira entende o fenômeno como sendo a adaptação das formas de trabalho ao novo processo produtivo, através do processo de negociaçãa ${ }^{11}$.

$\mathrm{O}$ autor faz menção, portanto, às inovações tecnológicas e às adaptações necessárias impostas ao capital pelo fenômeno da globalização.

Pode-se definir flexibilização da legislação trabalhista, portanto, como sendo o processo de acomodação das normas que regem as relações trabalhistas aos interesses e necessidades do capital, garantindo a coexistência pacífica de ambas estas forças: capital e trabalho.

Embora se objetive à coexistência pacífica destas duas forças, o processo de pacificação não exclui a derrogação de direitos trabalhistas adquiridos. A idéia, portanto, é pacificar capital e trabalho. Porém, jamais mediante sacrificio do capital.

\subsection{Posiçôes da doutrina}

Vozes levantam-se contra e a favor da implementação da flexibilização da legislação trabalhista nacional.

Romita ${ }^{12}$ entende que a proteção proporcionada pela legislação trabalhista brasileira ao trabalhador, na realidade dos fatos, redunda em desproteção. E a resultante dessa desproteção também desempenha uma função social: perpetuar a posição subalterna e submissa em que se encontra o trabalhador e justificar a necessidade de atuação dos protetores, protegendo (aqui sim, há proteção) a posição social ocupada pelos protetores.

Portanto, entende que a finalidade do princípio da proteção volta-se ao próprio Estado que o faz materializar através da legislação. Ou seja, uma vez perpetrada a submissão e subalternidade dos trabalhadores, estaria segura a posição social daqueles a quem servem os trabalhadores.

\footnotetext{
$"$ OLIVEIRA, L. J. de. Direito do Trabalho: Organização de Trabalhadores \& Modernização. Curitiba: Juruá, 2003. p. 69.

${ }^{12}$ ROMITA, A. S. O princípio da proteção em xeque. In: Revista LTr, junho/2002. São Paulo: LTr, 2002, $66-06$, p. $655-662$.
} 
Trata-se, sob sua ótica, de proteger sim o capital a que o trabalho serve.

Para Romita, existe a necessidade de uma reforma constitucional profunda como forma de preparar o país para os novos tempos, admitir a autonomia sindical autorizada pela Constituição Federal, dar ênfase à negociação coletiva e emprestar democrática e atualizada regulação ao direito de greve.

A opção por esta via implica necessariamente na supressão daquilo que, no Texto de 1988, reverencia o autoritarismo e o corporativismo que remontam a 1937, causa dos desajustes sociais que se verificam nos dias atuais.

A compatibilização entre flexibilização e os princípios constitucionais norteadores do Direito do Trabalho (materializado através dos vários dispositivos constitucionais acima declinados) tem sido analisada sob vários aspectos.

Como a Constituição autoriza a negociação coletiva in pejus em alguns temas (art. 7ª , VI e XIII), a interpretação do preceito constitucional deveria dar-se de forma restrita, ou seja, somente quando presente autorização constitucional o negociado poderia sobrepor-se ao legislado.

Portanto, a flexibilização somente está autorizada a tratar a questão da redução do salário e da jomada, vez que presente preceito da Lei Maior permissivo neste sentido ${ }^{13}$.

Amauri Mascaro tece as seguintes críticas a este posicionamento:

Do fato de a Constituição ter autorizado redução de salário e de jornada pela negociação coletiva e silenciado sobre outros dos seus dispositivos não se pode inferir que a flexibilização dos demais direitos esteja maculada pelo vício da inconstitucionalidade, na medida em que os direitos estabelecidos pela Constituição devem ser respeitados por todo projeto que preveja a flexibilização. ${ }^{14}$

É o caso do Projeto de Lei (PL) 5.483/2001 que contém expressa disposição no sentido de que as condições de trabalho ajustadas mediante convenção ou acordo coletivo prevalecem sobre o disposto em lei, desde que não contrariem a Constituição Federal e as normas de segurança e saúde do trabalhador.

A segunda crítica dá-se no sentido de que a autorização constitucional para a validade das convenções coletivas não se reduz a um tema específico, é genérica, como se vê do disposto no art. 7ª̣, XXVI, que declara reconhecimento das convenções e acordos coletivos de trabalho, com o que nada mais seria necessário, no ordenamento jurídico, em face do comando constitucional, para a validade do negociado, in mellius ou in pejus, à falta de restrição do referido texto.

\footnotetext{
${ }^{13}$ NASCIMENTO, A. M. Limites da Negociação Coletiva na perspectiva do projeto de flexibilização da CLT. In: Revista LTr, Dezembro/2001. São Paulo: LTr, 2001, p.1430-1.

${ }^{14}$ NASCIMENTO, A. M. Limites da Negociação Coletiva na perspectiva do projeto de flexibilização da CLT. In: Revista LTr, Dezembro/2001. São Paulo: LTr, 2001, p.1431.
} 
Defende ainda o autor que interpretar a Constituição somente sob o enfoque dos incisos VI e XIII constituir-se-ia em uma interpretação não sistêmica, o que redundaria em equívoco.

E finaliza argumentando que se a lei constitucional autoriza a sobreposição do negociado sobre o legislado quanto a salários, está, implicitamente, fazendoo quanto ao mais, sabendo-se que o salário é o direito alimentar maior do empregado, não tendo sentido, nesse caso, negar o menos e autorizar o mais.

A palavra final, no entanto, caberá ao guardião da Constituição, o Supremo Tribunal Federal, o qual terá o papel primordial de analisar se a flexibilização se compatibiliza ou não com os princípios constitucionais norteadores do Direito do Trabalho, na medida que é de sua competência originária declarar a constitucionalidade ou inconstitucionalidade de determinado preceito legal ${ }^{15}$.

Portanto, ambas as teses encontram argumentos defensáveis, tanto aquela que se posiciona contra quanto a favor da flexibilização.

O que se mostra razoável e acorde com o sistema legislativo vigente é que o caminho inicial que se descortina para a compatibilização entre os princípios constitucionais norteadores deste ramo do Direito e a flexibilização, constitui-se na observância irrestrita dos direitos já conferidos aos trabalhadores pelo ordenamento constitucional.

Assim, ao se flexibilizar a legislação trabalhista brasileira, os direitos já contemplados pela Constituição não poderão ser contrariados, sob pena de violação direta da Lei Maior, fato este vedado pelo Ordenamento Jurídico.

O pactuado, portanto, não poderá se sobrepor à norma constitucional, sendo razoável supor-se tal critério como forma de se compatibilizar flexibilização com princípios constitucionais de Direito do Trabalho.

\section{A flexibilização no direito brasileiro}

O período de transição entre os séculos $\mathrm{XX}$ e XXI vem sendo marcado por transformações de ordem global, gerando momentos delicados para os países em desenvolvimento, como é o caso do Brasil. A adoção do sistema econômico neo-liberal, com privilégio do capital em relação ao trabalho, mas sem implementação de uma política voltada aos problemas sociais, gera maior desigualdade na distribuição de renda.

${ }^{15}$ BRASIL Constituiçăo da República Federativa do Brasil. Brasilia: Senado Federal, 2002, artigo 102, \$2", p. 73. 
Em razão de interesses de grupos macro-econômicos a desvalorização do real em relação ao dólar fez com que os preços ao consumidor fossem disparados, o que redundou em uma inflação de 19,26\% no ano de 2002 -aferida pelo IGPM, com pesquisa realizada pela Fundação Getúlio Vargas, observados os onze primeiros meses do ano. ${ }^{16}$

A instabilidade política, gerada pela vitória da oposição trabalhista na eleição presidencial fez com que o Risco-Brasil ${ }^{17}$ disparasse, gerando a possibilidade de os investimentos estrangeiros serem retirados do País - dada a possibilidade de não cumprimento pelo governo sucessor dos contratos firmados pelo governo anterior com entidades financeiras internacionais.

Portanto, ao menos neste período de transição governamental, tanto no âmbito político quanto social e econômico, paira uma certa instabilidade no ar.

Neste cenário, cabe analisar os aspectos do projeto de Lei que propõe a adoção da flexibilização.

\subsection{Análise do Texto do Projeto}

Aprovado pela Câmara dos Deputados, mesmo a contra-gosto das classes trabalhadoras, o substitutivo ao projeto de Lei 5.483/2001 segue para ser votado no Senado Federal com uma série de incorreções técnicas e traduzindo a incerteza até mesmo do Poder Legislativo no que se refere à viabilidade ou não de sua implementação no cenário sindical brasileiro.

De autoria do Poder Executivo, o PL 5.483/2001 visa alterar o artigo 618 da CLT (Decreto-Lei 5.452, de $1^{\text {a }}$ de Maio de 1943), estabelecendo que as condições de trabalho ajustadas mediante convenção ou acordo coletivo prevalecem sobre o disposto em lei, desde que não contrariem a Constituição Federal e as normas de segurança e saúde do trabalho.

Pelo texto apresentado, a redação do artigo 618 da CLT disporia da seguinte forma: As condições de trabalho ajustadas mediante convenção ou acordo coletivo de trabalho prevalecem sobre o disposto em lei, desde que não contrariem a Constituição Federal e as normas de segurança e saúde do trabalho.

Em tumultuada sessão ocorrida em Dezembro de 2001, a Câmara dos Deputados aprovou o substitutivo ao referido projeto, assim fazendo constar:

Art. $1^{\text {a }} \mathrm{Na}$ ausência de convenção ou acordo coletivo, firmados por manifestação expressa da vontade das partes e observadas as demais disposições do Título VI desta Consolidação, a lei regulará as condições de trabalho.

$\S 1$ a A convenção ou acordo coletivo, respeitados os direitos trabalhistas

\footnotetext{
"DESVALORIZAÇÃO do real dispara preços. Folha de Londrina, Londrina, Cademo Economia, p. 3, 22/11/2002. ${ }_{17}$ Índice econômico que afere a confiabilidade de investidores estrangeiros no País.
} 
previstos na Constituição Federal, não podem contrariar lei complementar, as Leis ns 6.321, de 14 de abril de 1976, e 7.418, de 16 de dezembro de 1985, a legislação tributária, a previdenciária e a relativa ao Fundo de Garantia do Tempo de Serviço - FGTS, bem como as normas de segurança e de saúde do trabalho.

$\$ 2^{-}$Os sindicatos poderão solicitar o apoio e o acompanhamento da central sindical, da confederação ou federação a quem estiver filiados, quando da negociação de convenção ou acordo coletivo previstos no presente artigo.

Art. $2^{a}$ Esta lei entra em vigor na data de sua publicação e tem vigência de dois anos.

Assim, com a aprovação do projeto, as empregados e empregadores estão autorizados a negociar diretamente as condições de trabalho, respeitados os direitos previstos na Constituição Federal.

\subsubsection{Discussôes acerca do Artigo $1^{a}$ e parágrafos}

Primeiramente cumpre ressaltar a ânsia do Legislativo Brasileiro em fazer constar expressões desnecessárias nos textos legais que aprova.

Não existe, no ordenamento jurídico vigente, convenção ou acordo coletivo que não sejam firmados por manifestação expressa da vontade das partes. Ou seja, tais tratativas não podem ser empreendidas de forma tácita.

Portanto, aqui o primeiro atecnicismo.

O Art. $1^{\underline{a}}$ pretende conferir prioridade à convenção e ao acordo coletivo na regulação das condições de trabalho em detrimento à lei.

No entanto, como bem colocado por Antonio Álvares da Silva ${ }^{18}$, a norma negociada só substituirá a legal nos casos em que haja norma de natureza apenas dispositiva ou anomia, ou seja, falta de ocupação legislativa em relação à matéria. Haverá então um espaço vazio que pode ser preenchido pela negociação coletiva.

Conjugando-se as disposições contidas no caput e no parágrafo $1^{\mathrm{a}}$ do substitutivo, confe-se poder aos instrumentos coletivos no que se refere a normatização das condições de trabalho, impondo à negociação coletiva limites mínimos taxativamente previstos.

is SILVA, A A. Flexibilização das Relações de Trabalho. São Paulo: Ltr, 2002 , p. 88. 
Ou seja, o caput do artigo $1^{\underline{a}}$ nada diz por si mesmo e só tem sentido se analisado em conjunto com o $\$ 1^{a}$, já que este dispositivo indica de forma expressa os limites objetivos a serem observados pelas tratativas coletivas que, segundo autoriza, regeriam preferencialmente as condições de trabalho.

Uma crítica que se pode fazer sobre o parágrafo primeiro é que, ao preceituar que $A$ convenção ou acordo coletivo, respeitados os direitos trabalhistas previstos na Constituicão Federal, o texto comete outro atecnicismo, na medida em que confere sentido de que todos os direitos trabalhistas previstos na Constituição poderiam ser negociados.

De acordo com o modelo kelseniano, há hierarquia entre normas quando a norma inferior tem seu fundamento na validade em regra superior. $\mathrm{O}$ conteúdo de validade ou não de uma norma decorre da comparação segundo o critério de localização na hierarquia das normas, no sentido de que a regra inferior retira seu fundamento de validade da norma superior, sem contrariá-la, pois, se houver contradição, considerase inválida a norma inferior. A lei deve ser elaborada conforme as regras formais previstas na norma superior. ${ }^{19}$

Assim, na visão de Kelsen, a Constituição é a fonte das normas gerais produzidas por via legislativa $e$, conseqüentemente, é hierarquicamente superior às demais normas, razão pela qual se mostra inócuo ressalvar a impossibilidade de qualquer norma inferior se sobrepor ao seu conteúdo.

Resta analisar, portanto, tendo em vista as disposições constitucionais e os princípios que regem o Direito do Trabalho, se o ordenamento jurídico brasileiro autoriza a sobreposição do negociado sobre o legislado, conforme pretende o texto aprovado.

O princípio da aplicação da norma mais benéfica ao empregado constitui-se em um dos pilares do Direito do Trabalho, razão pela qual foi erigido a nível constitucional.

Partindo-se do princípio de que o texto Constitucional não contém expressões ociosas, constata-se a positivação de tal princípio, ao preceituar no caput do artigo $7^{a}$ que São direitos dos trabalhadores urbanos e rurais, além de outros que visem à melhoria de sua condição social.

Dentre os direitos elencados, o inciso XXVI contempla o reconhecimento das convenções e acordos coletivos de trabalho.

\footnotetext{
19 MARTINS, S. P. Direito do Trabalho, $17^{\circ}$ ed., São Paulo: Atlas, 2003, p. 67
} 
As tratativas coletivas, convenções e acordos gozam do reconhecimento constitucional. No entanto, são elencados dentre aqueles instrumentos que devem visar melhoria da condição social do trabalhador, além de outros sobre os quais a legislação infraconstitucional já tenha disposto.

Encontram, portanto, sua origem esua limitação no próprio texto constitucional, podendo somente contemplar condições mais benéficas ao trabalhador.

Juntamente com o princípio da norma mais benéfica, o princípio da condição mais favorável ao trabalhador se encontra sedimentado no ordenamento jurídico internacional. Preceitua o artigo 19, VIII da Constituição da Organização Internacional do Trabalho $(\mathrm{OIT})^{20}$, que:

Em caso algum, a adoção, pela Conferência, de uma convenção ou recomendação, ou a ratificação, por um Estado-Membro, de uma convenção, deverão ser consideradas como afetando qualquer lei, sentença, costumes ou acordos que assegurem aos trabalhadores interessados condições mais favoráveis que as previstas pela convenção ou recomendação.

Tal vedação demonstra a preocupação da instituições que regulam o Direito Internacional do Trabalho no sentido de que sempre prevaleça a norma que preveja condição mais favorável ao trabalhador, sobre o qual se fundam as normas internas do ordenamento jurídico nacional.

José Affonso Dallegrave Neto ${ }^{21}$ defende a inconstitucionalidade da proposta, na medida em que os direitos trabalhistas previstos na Constituição Federal se constituiriam, sob sua ótica, em cláusulas pétreas. Para ele, um argumento que refuta a validade da proposta de prevalência do negociado em prejuízo do já assegurado no legislado é o enquadramento dos direitos sociais, incluindo-se aí os direitos trabalhistas do art. $7^{a}$ da CF, como cláusulas pétreas.

Isso porque a Constituição Federal estabelece no Art. 60 , $\S 4^{\mathrm{a}}$, IV que não será objeto de deliberação a proposta de emenda tendente a abolir os direitos e garantias individuais.

Portanto, para referido autor, se os direitos trabalhistas consignados no Art. $7^{a}$ da Constituição Federal sequer podem ser objeto de Emenda Constitucional, igualmente não pode haver supressão de regulamentação legal mediante negociação coletiva. Assim, é inadmissível que tanto o ACT como a CCT tenham o condão de revogar direitos trabalhistas contemplados na Consolidação das Leis do Trabalho ou qualquer outra lei esparsa ${ }^{22}$.

\footnotetext{
21) Disponivel em: hutp//www iloorg/public/portugue/resion/ampro/brasila/info/download/ constituicao oitpd. Acesso em: 02 Jul 2003

${ }^{2 !}$ DALLEGRAVE NETO, ]. A. Inovaçöes na Legislação 'Trabalhista. Reforma Trabalhista Ponto a Ponto, $2^{g}$ ed., São Paulo: LIr, 2002, p. 47-48.

${ }^{22}$ DALLEGRAVE NETO, ]. A. Inovações na Legislação Trabalhista. Reforma Trabalhista Ponto a Ponto, $2^{2}$ ed., Sào Paulo: $\mathrm{LTr}_{\mathrm{r}} 2002$ p. 48.
} 
Portanto, sob o prisma colocado, a proposta é inconstitucional. Aliás, tarefa das mais dificeis é a de encontrar jurista na defesa do projeto, analisando-se seus aspectos tendo sob prisma o contexto normativo em que se baseia.

Econômica e politicamente, a proposta governamental é defensável. Ao justificar o pedido de urgência para a votação do então Projeto de Lei, - Ministro do Trabalho e Emprego manifestou-se dizendo que está convencido de que o projeto ajudará a salvar um grande número de postos de trabalho. Sob seu ponto de vista, não há supressão de direitos dos trabalhadores, mas mais e melhores condições para os sindicatos negociarem. ${ }^{23}$

Facilmente perceptível a incompatibilidade entre a proposta do governo e o ordenamento jurídico vigente e igualmente o esforço à positivação do texto já aprovado, utilizando-se da propalada salvação de postos de trabalho como forma de convencimento da opinião pública.

Cabe ao Senado Federal levar em conta os argumentos indicado a inconstitucionalidade do dispositivo em análise ao proceder à sua votação. Se aprovado, o substitutivo acabará por ter decretada sua inconstitucionalidade pelo Supremo Tribunal Federal.

O parágrafo $2^{3}$ do substitutivo aprovado preceitua que os sindicatos poderão solicitar o apoio e o acompanhamento da central sindical, da confederação ou federação a quem estiver frliados, quando da negociação de convenção ou acordo coletivo previstos no presente artigo.

O Direito Coletivo Brasileiro encontra suas bases na Constituição Federal e nos Títulos V e VI da Consolidação das Leis do Trabalho (CLT).

Uma primeira observação que se pode tecer com relação ao dispositivo em análise, é que a instituição das centrais sindicais não se encontra normatizada no Direito Coletivo Nacional, na medida em que a CLT nada dispõe a seu respeito. Ou seja, inexiste previsão legal a lhe conferir existência jurídica.

Por outro lado, o texto inicia por contrariar preceito legal já consolidado no ordenamento jurídico, na medida em que o inciso III do artigo $8^{a}$ da Constituição da República estabelece que ao sindicato cabe a defesa dos direitos e interesses coletivos ou individuais da categoria, inclusive em questões judiciais ou administrativa ${ }^{24}$. 
A norma infraconstitucional também estabelece que cabe aos sindicatos a pactuação de acordo e convenção coletiva ${ }^{25}$, a deliberação acerca de paralisação do trabalho, a fim de exercer o direito de greve $\mathrm{e}^{26} \mathrm{e}$ a propositura de dissídios coletivos ${ }^{27}$.

As centrais sindicais têm como finalidade firmar a política econômica e social dos representados, dialogar com o governo e autoridades públicas, participar de discussões sobre projetos de lei e ações governamentai ${ }^{28}$.

Embora constituam instituições não previstas em lei e, portanto, não integrantes do Direito Coletivo brasileiro para fins de prática de atos sindicais, já fazem parte da realidade nacional, quer seja através do diálogo com as instituiçôes governamentais, quer seja sendo incumbida de determinadas obrigações por leis infraconstitucionais.

É o caso do $\S^{3}$ do artigo $3^{\text {a }}$ da Lei $8.036 / 90$, o qual preceitua que os representantes dos trabalhadores e dos empregadores e seus respectivos suplentes serão indicados pelas respectivas centrais sindicais e confederações nacionais e nomeados pelo Ministro do Trabalho e da Previdência Social, e terão mandato de 2 anos, podendo ser reconduzidos uma única vezz".

Portanto, as centrais sindicais já têtn garantido papel de destaque no Direito Coletivo brasileiro, influindo até mesmo em órgãos de relevante importância, como é o caso do Conselho Curador do FGTS.

A menção do projeto governamental às centrais sindicais constituiuse, na prática, no reconhecimento oficial de seu valor e do papel que desenvolve no movimento sindical nacional.

Por outro lado, também permite a leitura no sentido de que os sindicatos representativos de categorias de empregados podem não ser tão fortes para negociar com os sindicatos patronais.

$\mathrm{E}$, infelizmente, tal fato é real. A negociação coletiva, como os demais atos sindicais, não raras vezes se constrói sob a finalidade de beneficiar os detentores do capital em detrimento dos trabalhadores.

Assim, a possibilidade de que os sindicatos se socorram de auxílio das entidades que the são superiores demonstra a preocupação do legislativo no sentido de que tal negociação, embora tenha o prećpuo objetivo de servir aos interesses do capital, possa também conferir um mínimo de proteção aos trabalhadores.

\footnotetext{
${ }^{25}$ BRASIL. Consolidação das Leis do Trabalho. Organização e coordenaçăo dos textos, notas remissivas e indices por Armando Casimiro Costa, Irany Ferrari e Melchíades Rodrigues Martins. $30^{\circ}$ ed. São Paulo: LTr, 2003 , artigo 612 , p. 209

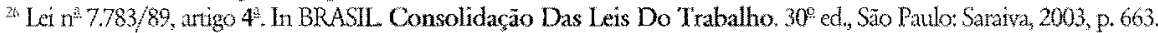
2 BRASIL Consolidação das Leis do Trabalho. Onzanização e coordenaç̧o dos textos notas remissivas e indices por Amando Casimito Costa, Iraty Ferrarie Melchiads Rodrigues Martirs. 30 ed. Săo Patlo. LT, 2003, autigo 857, p. 285.

sILVA, A. A. Flexibilização das relaçöes de trabalho, São Paulo: LTr, 2002, p. 95.

20 Tratrse da Lei que dispǒes sobre o Fundo de Garantia do Tempo de Serviço - FGTS - sendo que o caput relativo a este parágrafo trata da representaço de seu Conselho Curador, ao qual compete tragar nomas e diretrizes para sua regência.
} 
Traduz, igualmente, a necessidade de constituir novas formas de organização de trabalhadores ou de aperfeiçoamento das já existentes para que ocorra uma autêntica flexibilização, com vistas a evitar o desemprego e atender aos interesses socrais ${ }^{30}$.

O que demonstra que o modelo sindical nacional não mais responde aos anseios dos trabalhadores, fato este que vem sendo até mesmo reproduzido por meio dos textos legais, ratificando a necessidade de se repensarem as estruturas sindicais da forma como se encontram.

\subsubsection{Análise do artigo $2^{a}$}

Ao limitar a vigência da lei em dois anos, o legislador deixa clara sua consciência de que o projeto anda na contra-mão da história do Direito do Trabalho no país e também representa riscos aos direitos trabalhistas já adquiridos, razão pela qual resolveu limitar a experiência a dois anos.

Novamente não foi feliz na medida, já que as relações jurídicas necessitam de um clima de segurança onde possam desenvolver-se.

Como há controvérsias no que tange à eficácia da medida proposta e quanto à competência das entidades sindicais na condução do projeto, houve por bem limitar a vigência da lei em dois anos.

Cabe ao Senado decidir pela manutenção da limitação, pela rejeição ou aprovação do projeto, conferindo assim certeza ou incerteza ao cenário social onde as relações que se the serão originárias passarão a ser desenvolvidas.

\section{Conclusão}

O texto do substitutivo ao projeto lei aprovado pela Câmara dos Deputados deixa claro que nem mesmo o Governo ${ }^{31}$ aposta na eficácia do instituto da flexibilização da legislação trabalhista.

Como visto, texto aprovado é alvo de críticas tanto por causa das incorreções técnicas existentes, quanto pelo fato de seu conteúdo se chocar frontalmente com o ordenamento jurídico constitucional e infra-constitucional.

Os direitos conquistados pela classe trabalhadores não raras vezes tiveram sua origem manchada pelo sangue das revoluções operárias que pretendiam se fazer ouvir pela classe daqueles que detinham os meios de produção.

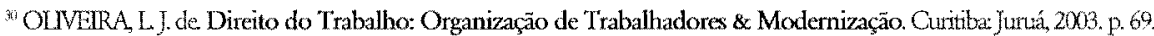
3! Ja que a inciativa da apresentaģo do projeto foi do Executivo.
} 
É fato que o mundo passa por transformações e o modelo produtivo exige algumas adaptaçôes para a viabilidade da convivência pacífica e inseparável com o trabalho.

Há necessidade de se repensar uma forma do modelo produtivo ser menos onerado e quanto a isto não há dúvida. No entanto, a idéia que se mostra razoável é que nos países em desenvolvimento, como é o caso do Brasil, não é apenas o excesso de direitos trabalhistas que inviabilizam ou causam dificuldades às empresas, até porque os direitos trabalhistas existentes no Brasil não ultrapassam o patamar básico de direitos conferidos aos trabalhadores.

$O$ que se denota é que existe um excesso de encargos sobre os direitos trabalhistas, os quais acabam por onerar o empregador e gerar a diminuição de postos de trabalho, ou, ainda, incentivar a adoção de práticas tendentes à redução destes encargos, tais como a anotação de parcela inferior ao real valor pago a título de remuneração, o conhecido pagamento extra follha.

O Projeto de Lei que acabou sendo aprovado pela Câmara dos Deputados permite que as tratativas coletivas, convenção ou acordo, passem a regular os direitos trabalhistas de forma prevalente à legislação já consolidada no ordenamento jurídico.

No entanto, os sujeitos que são parte em tais tratativas são empregado e empregador, representados pelas respectivas entidades de classe. Isto significa que o problema central da questão do desemprego que, ao que tudo indica, reside no excesso de encargos tributários e previdenciários sobre os valores pagos aos empregados, não será sequer minimizado.

Se o fenômeno da flexibilização tem sua origem na economia e a idéia é a de flexibilizar o ordenamento jurídico, a conclusão que se chega é que referido instituto garante o fortalecimento do capital. $\mathrm{E}$ isso não será possível através da criação de direitos.

Portanto, caso o substitutivo seja aprovado pelo Senado Federal, a classe trabalhadora deverá estar atenta, já que o objetivo final da flexibilização indica para o fortalecimento do capital.

Nesta hipótese, de aprovação da proposta, os próximos dois anos terão vital importância na demonstração dos efeitos práticos do instituto, observada a independência sindical e a necessidade do fortalecimento de tais instituições.

É imperativo repensar a liberdade de o empregado filiar-se a esta ou aquela entidade sindical, o que hoje não ocorre no Direito Coletivo brasileiro, bem como o princípio da unicidade sindical ${ }^{32}$.

\footnotetext{
BRASIL Constituiçäo da República Federativa do Brasil. Btasilia: Senado Federal, 2002, artigo 8, II, p.22.
} 
Uma negociação coletiva plena só encontra foros de efetividade em clima de liberdade sindical, já que exige na representação dos trabalhadores, entidades sindicais autênticas e fortalecidas. $\mathrm{O}$ movimento sindical brasileiro, em sua vertente oficial, não exibe tais características. Não há dúvida, porém, de que os sindicatos filiados às centrais sindicais mais atuantes, como a CUT, a Força Sindical e a Social Democracia Sindical podem desincumbir-se a contento da tarefa que o projeto lhes atribui: negociar condições de trabalho à margem da lei como contra-poder eficaz em face do poder econômico e estatal ${ }^{33}$.

Assim, as condições política-econômica-sociais - e sindical - vividas pelo nosso Estado no limiar do século XXI não permitem igualdade às partes - capital e trabalho - de levarem a efeito negociação coletiva que autorize a sobreposição do negociado sobre o legislado.

Por outro lado, a vitória oposicionista na eleição presidencial, pode constituir-se em marco histórico inicial do fortalecimento do movimento sindical nacional, na medida em que a Presidência do Estado - exercida desde início de 2003 pelo Partido dos Trabalhadores - nasceu no âmbito sindical.

Conclui-se, pois, que sob o cenário que ora se descortina inexistem condições de igualdade para que capital e trabalho negociem os direitos trabalhistas a fim de sobrepô-los às leis que os originaram.

E, a inexistência de condições para que tal fato se dê, não reside apenas em âmbito fático, encontrando igualmente óbice legal e constitucional, como colocado acima.

Assim, caso o projeto se transforme em lei, a incerteza nas relações juridicas não advirá apenas do período de vigência limitada desta norma - dois anos - mas também dos questionamentos judiciais que serão levados ao Supremo Tribunal Federal, com a finalidade de ver declarada sua inconstitucionalidade.

Neste contexto, não há como se afirmar, com certeza, se a flexibilização das normas que regem os direitos trabalhistas se constitui em solução ao desemprego ou em um problema a mais a ser administrado pela sociedade brasileira.

\section{BIBLIOGRAFIA}

BRASIL. Consolidação das Leis do Trabalho. Organização e coordenação dos textos, notas remissivas e índices por Armando Casimiro Costa, Irany Ferrari e Melchíades Rodrigues Martins. $30^{\circ}$ ed. São Paulo:

${ }^{33}$ ROMITA, A. S. O princípio da proteção em xeque. In: Revista LTr 66-06, Junho/ 2002, p.655. 
LTr, 2003.

BRASIL. Constituição da República Federativa do Brasil. Brasília: Senado Federal, 2002.

DALLEGRAVE NETO, J. A. Inovações na Legislação Trabalhista. Reforma Trabalhista Ponto a Ponto, $2^{\circ}$ ed., São Paulo: LTr, 2002.

FILHO DA COSTA, O. T. apud SÜSSEKIND, A.; MARANHÃO, D; VIANNA, S.; TEIXEIRA, L. Instituições de Direito do Trabalho. $18^{\circ}$ ed., Vol I , São Paulo: LTr, 1999.

KELSEN, H. Teoria Pura do Direito. Tradução: João Baptista Machado. 5ำed., São Paulo: Martins Fontes, 1996.

MARTINS, S. P. Direito do Trabalho, $17^{\circ} \mathrm{ed}$., São Paulo: Atlas, 2003. MARTINS, S. P. Flexibilização das Condições de Trabalho, São Paulo: Atlas, 2000.

NASCIMENTO, A. M. Curso de Direito do Trabalbo. $17^{\circ}$ ed., São Paulo: Saraiva, 2001.

NASCIMENTO, A. M. Direito do Trabalho na Constituição de 1988. São Paulo: Saraiva, 1989.

NASCIMENTO, A. M. Limites da Negociação Coletiva na perspectiva do projeto de flexibilização da CLT. In: Revista LTr, Dezembro/2001. São Paulo: LTr, 2001.

OLIVEIRA, L. J. de. Direito do Trabalho: Organização de Trabalhadores \& Modernização. Curitiba: Juruá, 2003.

ROMITA, A. S. O princípio da proteção em xeque. In: Revista LTr, junho/2002. São Paulo: LTr, 2002, 66-06.

SILVA, A. Á Flexibilização das Relações de Trabalho. São Paulo: Ltr, 2002. SÜSSEKIND, A; MARANHÃO, D.; VIANNA, S.; TEIXEIRA, L Instituiçōes de Direito do Trabalho. São Paulo: LTr, 1999. 